\title{
25 Research Soure \\ Comparison of Standard and Point of Care CD4+ T Lymphocyte Measurement Methods in HIV-1 Infected Turkish Patients
}

Müge Toygar Deniz ( $\square$ mugedeniz90@gmail.com )

Kocaeli Devlet Hastanesi

\section{Sila Akhan}

Kocaeli University

Murat Sayan

Kocaeli University

\section{Research Article}

Keywords: CD4-Positive T-Lymphocytes, Flow Cytometry, HIV, Point-of-Care Testing

Posted Date: August 23rd, 2021

DOI: https://doi.org/10.21203/rs.3.rs-806068/v1

License: (c) (i) This work is licensed under a Creative Commons Attribution 4.0 International License.

Read Full License 


\section{Abstract}

Background and Objectives: CD4 + T lymphocytes are the primary targets of HIV infection. Absolute CD4 + T lymphocyte count is an indicator of immune competence in evaluating the stage of the disease, delayed diagnosis, need for prophylaxis against opportunistic infections and the treatment success. In this study, we aimed to compare standard flow cytometry and point of care CD4 + T lymphocyte measurement analysis techniques in terms of cost, effectiveness, compliance, reliability, time and the use of this method for disease progression for the HIV-1 infected Turkish patients.

Methods: This study includes 116 patients with chronic HIV infection. Patients under treatment, over 18 years old are included. CD4 + T lymphocyte count and percentage were enumerated by flow cytometry, which is the gold standard method. Also hemoglobin level was studied. These parameters were also studied with a new POC method called Cartridge. The data obtained by two methods are compared.

Results: Of the 113 patients, 96 (85\%) were male, 17 (15\%) were female, and the mean age of the group was 43. When compared two methods, Spearman's correlation coefficients demonstrated good correlation for hemoglobin $(r=0.764)$. For CD $4+T$ lymphocyte measurements, correlation coefficients were lower ( $r=0.725$ and 0.515 respectively) but still

statistically significant $(p<0.001)$. According to Bland-Altman analysis, the average difference for hemoglobin shows strong correlation for different measurements.

Conclusions: In resource-limited countries, not all patients can receive ART. Therefore, this test is important in order to instantly detect patients who are in urgent compliance to initiate treatment with CD4 measurement. Hemoglobin measurement is the best parameter between the two methods that can be compared in our opinion because it is determined in a more standardized way. As we found in our study, the high correlation of hemoglobin values may give an idea about the reliability of the new method.

\section{Introduction}

Human immunodeficiency virus (HIV) infection continues to increase globally. According to the latest Joint United Nations Programme on HIV/AIDS (UNAIDS) reports, 38 million people live with HIV worldwide and 26 million are able to access antiretroviral therapy; however, up to now, 690,000 people have died from AIDS-related diseases (1). In Turkey, HIV/AIDS detection has been implemented since 1985 and as of November 2020, the number of confirmed cumulative HIV-positive cases is 25,809, and the number of AIDS cases has reached 1958. The age groups with the highest number of cases are between $25-29$ and 30-34 years. It has been determined that $47.5 \%$ of HIV transmission was caused by sexual contact (2).

CD4 + T lymphocytes are the primary targets of HIV infection. The main cells infected by HIV are monocytes, tissue macrophages, natural killer cells, dendritic cells, hematopoietic stromal cells, and the microglial cells of the brain that carry the CD 4 receptor $(6,7)$. The CD 4 
+ T lymphocyte count decreased by an average of 58 cells / $\mu \mathrm{L}$ per year in a study of 276 untreated patients with chronic HIV infection (3). Accordingly, opportunistic infections and malignancies that are characteristic of AIDS can occur (5). Absolute CD4 + T lymphocyte count is an indicator of immune competence in evaluating the stage of the disease, delayed diagnosis, need for prophylaxis against opportunistic infections, and the treatment success. A normal CD $4+T$ lymphocyte count is $400-1600$ cells $/ \mathrm{mm}^{3}$, and below 350 cells $/ \mathrm{mm}^{3}$ indicates that the patient applied in a delayed state (8). Below 200 cells $/ \mathrm{mm}^{3}$ is an indicator of immunosuppression and vulnerability to opportunistic infections (4).

The current treatment approach is combination therapy, which simultaneously targets multiple gene regions in HIV (c-ART). Patients are followed up with virological (HIV RNA level) and immunological (CD4 $+T$ lymphocyte count and its' percentage of total lymphocyte count) tests. In addition to routine laboratory examinations, the CD4 + T lymphocyte count is checked every 3-6 months and the HIV RNA level every 6-12 months during follow-up (9). Measurement of CD4 + T lymphocyte count is most commonly done using flow cytometry. In this method, cells or particles in a suspension are analyzed by collecting their signals as they pass through a chamber illuminated by a laser source. The disadvantages of the method are that it is calculated relative to the total number of lymphocytes in the complete blood count and the result changes in intervening infections (10).

CD4 + T lymphocyte count is determined in laboratories where fresh EDTA blood taken from hospitals during the day is transferred and collected; the results can be obtained in an average of 2-14 days or over a longer time according to the capacity of the laboratory (11). For patients suffering from a chronic HIV infection, a rapid and accurate CD4 + T lymphocyte count may be required to rapidly begin treatment, determine the status of the infection, and prevent potential opportunistic infections. (12).

In this study, we aimed to compare standard flow cytometry and point of care (POC) CD $4+$ T lymphocyte measurement analyses in terms of cost, effectiveness, compliance, reliability, time, and the use of this method for disease progression for HIV-1-infected Turkish patients.

\section{Materials And Methods}

There were 113 HIV-1-infected patients who applied to the Kocaeli University Hospital, infectious diseases outpatient clinic for routine follow-up in 2019 included in this study. HIV treatment was applied according to current Turkish Republic Ministry of Health and EACS 2020 guidelines. Patients over 18 years of age and receiving ART treatment were included in the study. The patients who participated in the study were informed about the new CD $4+T$ lymphocyte measurement method. Consent forms were prepared according to the Helsinki declaration and the patients were informed accordingly.

CD4 + T lymphocytes were enumerated using the routine FACS count reference method (Becton Dickinson, San Jose, CA, USA). This method was most commonly done by flow cytometry and the cells or particles in a suspension were analyzed by counting the signals as they pass through a chamber illuminated by a laser source. The POC measurement method developed for rapid CD4 + T lymphocyte 
measurement used in our study employed a Cartridge (BD FACSPresto, San Jose, CA, USA) kit that used fluorochrome-conjugated antibody reagents and integrated reagent quality control. It consisted of fluorescence imaging and absorbance reading technology with embedded software to analyze patient samples from a single-use disposable cartridge. The indicators available from Cartridge are CD4 + T lymphocyte count and percentage and hemoglobin level, and it is a portable device that can give results in $25 \mathrm{~min}$. In addition, blood was drawn into an EDTA tube to determine the hemoglobin level from our patients. The demographic information of the patients was obtained from the hospital data system.

The data obtained by both methods were compared statistically by standard deviation, median, and CV\% analysis. After the data were collected, all evaluations were made at the same time.

Ethics approval was obtained from the Derince Training and Research Hospital Ethics Committee with the number 2021/64.

\section{Results}

There were 113 patients who were applied for treatment of chronic HIV disease included in our study. Demographic, laboratory, and medical findings of the patients were shown in Table 1. Among these patients, males ( $n=96,85 \%)$ predominated over females $(n=17,15 \%)$. The age of the patients ranged between 21 and 74 . The mean age of the patients was calculated as $43 \pm 13$ years. 
Table 1

Demographic, laboratory and medical findings of the patients

\section{Characteristic}

Patient, $\mathrm{n}$

Gender, M/F, n (\%),

Age, $($ mean $+S D)$,years

Basal HIV-1 RNA load, (mean + SD), IU/ml

Basal Standart CD4 + T lymphocyte count,

$($ mean $+S D)$, cells $/ \mu l$

Diagnostic status in CD4 + T lymphocyte count, cells/ $\mu \mathrm{l}, \mathrm{n}(\%)$

$\mathrm{CD} 4 \leq 100$

$100<\mathrm{CD} 4 \leq 350$

$350<\mathrm{CD} 4 \leq 500$

CD4 > 500

Treatment status, $\mathbf{n}(\%)$

$A B C+D T G+3 T C$

TDF/FTC/c/EVG

$\mathrm{TAF} / \mathrm{FTC} / \mathrm{c} / \mathrm{EVG}$

TDF/FTC + DTG

$\mathrm{TAF} / \mathrm{FTC} / \mathrm{BIC}$

$\mathrm{TDF} / \mathrm{FTC}+\mathrm{LPV} / \mathrm{r}$

$R A L+Z D V+T D F$

Abbreviations. M: male, F: female, MSM: men sex with men, CD: cluster of differentiation, $A B C$ : abacavir, DTG: dolutegravir, 3TC: lamivudine, EVG: elvitegravir, c: cobisistat, TDF: tenofovir disoproksil fumarate, FTC: emtricitabine, TAF: ten ofovir alafenamide, BIC: bictegravir, LPV: lopinavir, r:ritonavir, RAL: raltegravir, ZDV: zidovudine
Patient group

113

96 (85) /17 (15)

$43 \pm 13$

$1.7+\mathrm{E} 6 \pm 5.4+\mathrm{E} 6$

$435 \pm 302$
8 (10)

25 (31)

18 (22)

29 (36)
57 (50)

14 (12)

$33(30)$

1 (1)

The HIV-1 RNA could not be reach in 12 patients before starting treatment. In addition, the CD4 + T lymphocyte results of 80 patients were available in the data system. Before starting treatment, the average CD $4+T$ lymphocyte was 435 cells/ $\mu$ l and ranged between 15 and 1842 . There were eight patients with CD 4 counts below 100 cells/ $\mu$ land 25 patients with CD 4 counts below 350 cells/ $\mu$ l (delayed admission) before treatment. 
When asked how the patients were diagnosed with HIV, 25 patients (22\%) told us that they applied to the hospital because of symptoms, 14 patients (12\%) received their diagnosis during a check-up, seven (6\%) patients were diagnosed during a pre-intervention screening tests, and two patients $(2 \%)$ received their diagnosis in a screening test before blood donation.

Ten patients (8\%) were tested due to their partners' diagnoses. One person said he became HIV positive after getting a tattoo. Admission symptoms included clinical manifestations, such as diarrhea, dysuria, lymphadenopathy, weight loss, perianal abscess, and Kaposi sarcoma.

Nine patients had an opportunistic infection at the time of diagnosis. These were pulmonary tuberculosis, progressive multifocal leukoencephalopathy (PML), oral candidiasis, toxoplasma brain abscess, pneumocystis jiroveci pneumonia (PCP), cytomegalovirus (CMV) colitis, mycobacterium avium complex (MAC) infection, Kaposi sarcoma, and Hodgkin lymphoma. CMV colitis and PCP were seen together in one patient. MAC and PML were also seen in one patient who died. Eleven patients were hospitalized and started treatment; others continued their follow-up regularly.

Three patients had a co-infection with hepatitis B and their current HBV DNA was negative. Ten patients had syphilis. These patients' current HIV-1 RNA are negative under the prescribed treatment. None of our patients had HIV drug resistance.

In our study, the new CD4 + T lymphocyte count measurement method, called Cartridge, was also used as an analyzer. The key indicators were CD4 + T lymphocyte, percentage, and hemoglobin level, and these indicators were achieved via patients' fingertip blood or plasma sample. The Spearman correlation between the results obtained by the Cartridge method and the gold standard are shown in Table 2 . 
Table 2

The results and correlations between flow cytometry and cartridge techniques

\begin{tabular}{|c|c|c|c|}
\hline Measurement technique & $\begin{array}{l}\text { CD4 + T } \\
\text { lymphocyte count, } \\
\text { mm3/pl }\end{array}$ & $\begin{array}{l}\text { CD4 + T } \\
\text { lymphocyte } \\
\text { percentage (\%) }\end{array}$ & $\begin{array}{l}\text { Hemoglobin, } \\
\mathrm{mg} / \mathrm{dl}\end{array}$ \\
\hline Flow cytometry & $688 \pm 326$ & $31 \pm 12$ & $147 \pm 14$ \\
\hline Mean \pm SD & $649(441-889)$ & $29(23-39)$ & $150(139-157)$ \\
\hline \multicolumn{4}{|l|}{ Median (25th -75th per.) } \\
\hline Cartridge & $742 \pm 321$ & $29 \pm 9$ & $147 \pm 19$ \\
\hline Mean \pm SD & $685(500-949)$ & $30(24-36)$ & $149(139-161)$ \\
\hline \multicolumn{4}{|l|}{ Median (25th -75th per.) } \\
\hline \multirow{2}{*}{$\begin{array}{l}\text { Spearman's correlation } \\
\text { coefficient }(r) \\
p \text { value }\end{array}$} & 0.515 & 0.725 & 0.764 \\
\hline & $<0.001$ & $<0.001$ & $<0.001$ \\
\hline
\end{tabular}

Spearman's correlation coefficients demonstrated good correlation for hemoglobin (r:0.764) For CD4 measurements, correlation coefficients were lower: 0.725 and 0.515 respectively (Fig. 1). In addition, Bland-Altman analysis was performed to compare the two methods (Fig. 2). According to these analyses the average difference for hemoglobin shows strong correlation for different measurements (Table 3). 
Table 3

Bland Altman analysis results in study patients

\begin{tabular}{|c|c|c|c|}
\hline Parameter & $\begin{array}{l}\text { CD4 + T lymphocyte count, } \\
\mathrm{mm} 3 / \mu \mathrm{l}\end{array}$ & $\begin{array}{l}\text { CD4 + T lymphocyte percentage, } \\
\text { (\%) }\end{array}$ & $\begin{array}{l}\text { Hemoglobin, } \\
\mathrm{mg} / \mathrm{dl}\end{array}$ \\
\hline Mean & 54 & $-1,4$ & 0,25 \\
\hline $95 \% \mathrm{Cl}$ & $-7,07$ to 115,81 & $-3,15$ to 0,18 & $-2,10$ to 2,61 \\
\hline$p$ value & 0,08 & 0,08 & 0,82 \\
\hline SD & 329,65 & 8,9 & 12,6 \\
\hline $\begin{array}{l}\text { Lower } \\
\text { limit }\end{array}$ & $-591,74$ & $-19,01$ & $-24,55$ \\
\hline $95 \% \mathrm{Cl}$ & $-697,06$ to $-486,42$ & $-21,87$ to $-16,15$ & $-28,60$ to $-20,51$ \\
\hline $\begin{array}{l}\text { Upper } \\
\text { limit }\end{array}$ & 700,49 & 16,05 & 25,07 \\
\hline $95 \% \mathrm{Cl}$ & 595,17 to 805,80 & 13,19 to 18,90 & 21,02 to 29,11 \\
\hline
\end{tabular}

\section{Discussion}

Today, c-ART has been started for every patient diagnosed with chronic HIV infection independent of the CD4 + T lymphocyte count (10). Countries suffering a high HIV burden in sub-Saharan Africa are left with difficult decisions of when and how to implement the many new recommendations in resource-limited settings (19). Assessing the immune status in patients through POC CD4 + T lymphocyte count can identify advanced HIV disease, which should be prioritized for prophylaxis of opportunistic infections even if they are asymptomatic. Therefore, $\mathrm{CD} 4+\mathrm{T}$ lymphocyte measurement is still important in order to instantly detect patients who are in urgent need to initiate treatment.

In our study, the POC CD4 measurement method called Cartridge was used. The key indicators of this method were CD4 + T lymphocyte count, CD4 + T lymphocyte percentage, and hemoglobin level. Cartridge presented several major advantages. Since the machine weighs only $7 \mathrm{~kg}$, it is easily portable and patients can get their results in $25 \mathrm{~min}$. In addition, various printer options, limited blood volume requirements, and ease of use, coupled with the elimination of initial blood processing and the need to prepare reagents are all features that would increase patient compliance. A recent report from Africa showed that POC CD4 testing could successfully reduce the pretreatment loss to follow-up (16).

The CD $4+T$ lymphocyte count was measured by the gold standard (flow cytometry) and was then compared to the Cartridge method, it was seen that the two methods were correlated $(r=0.515, p<0.001$, Table 2). The results obtained using the standard method (a venous blood sample) were compared and the CD4 + T lymphocyte count from Cartridge was also found to be correlated $\left(r^{2}=0.087\right)(20)$. In the 
pediatric age group (individuals under 5 years of age), the $C D 4+T$ lymphocyte percentage is considered a more reliable surrogate marker for immunological status of patients diagnosed with chronic HIV infection (18). As seen in Table 2, the fact that this parameter was significantly correlated between both methods in our study may be another reason for the use of the new method.

In addition, the hemoglobin test is very important in terms of detecting drug toxicity that develops due to zidovudine, which is frequently used in resource-limited countries. In addition, Zelda et al. intimated that it could also be particularly valuable in preventing mother to child transmission (PMTCT) programs (17). The level of the hemoglobin is the best parameter between the two methods that can be compared in our opinion because it is determined in a more standardized way. Therefore, the high correlation of hemoglobin values in our study provides insight regarding the reliability of the new method.

Our Bland-Altman analysis demonstrated a strong correlation of the hemoglobin levels between the two methods like a similar study in Uganda reported (15); however, this is not the

case for the CD4 measurements (Fig. 2). For the CD4 + T lymphocyte count, there is greater error in higher values. In these cases, the flow cytometry data tend to report higher than expected levels of $C D+T$ lymphocytes; however, the difference does not seem to exceed $12 \%$. Therefore, the most accurate parameter to conclude the reliability of the new method is the hemoglobin measurement, which is also associated with Spearman analysis in Fig. 1. $(r=0.764, p<0.001)$.

\section{Conclusion}

As we found in our study, the high correlation of hemoglobin values may give an idea about the reliability of the new method, and POC technology is a cost-effective alternative that increases patient compliance, especially in resource-limited regions.

\section{Declarations}

Ethics approval and consent to participate: Ethics approval was obtained from the Derince Training and Research Hospital Ethics Committee with the number 2021/64.

Consent for publication: Not applicable.

Availability of data and materials: Yes.

Competing interest: No interest.

Funding: No funding.

Authors' contributions: MTD: Writing, SA:Design of the study, MS:Last revision

Acknowledgements: Not applicable. 


\section{References}

1. The Joint United Nations Programme on HIV/AIDS. Last accessed date: 2021 April 26. Available from: https://www.unaids.org/en

2. T.C. Sağlık Bakanlığı Halk Sağlığı Genel Müdürlüğü. Last accessed date: 2021 April 26. Available from: https://hsgm.saglik.gov.tr/tr/bulasici-hastaliklar/hiv-aids/hiv-aids- liste/hiv-aids-istatislik.html

3. Tan DHS, Raboud JM, Szadkowski L, Grinsztejn B, Madruga JV, Figueroa MI, et al. Effect of valaciclovir on CD4 count decline in untreated HIV: an international randomized controlled trial. J Antimicrob Chemother. 2019;74(2):480-488.

4. Mofenson LM, Brady MT, Danner SP, Dominguez KL, Hazra R, Handelsman E, et al. Guidelines for the Prevention and Treatment of Opportunistic Infections among HIV-exposed and HIV-infected children: recommendations from CDC, the National Institutes of Health, the HIV Medicine Association of the Infectious Diseases Society of America, the Pediatric Infectious Diseases Society, and the American Academy of Pediatrics. MMWR Recomm Rep. 2009;58(RR-11):1-166.

5. Vaillant AA, Naik R. HIV-1 Associated Opportunistic Infections. In: StatPearls Publishing; 2021 Jan.

6. Henry DH, Beall GN, Benson CA, Carey J, Cone LA, Eron LJ, et al. Recombinant human erythropoietin in the treatment of anemia associated with human immunodeficiency virus (HIV) infection and zidovudine therapy. Overview of four clinical trials. Ann Intern Med. 1992;117(9):739-48.

7. Paton $\mathrm{NI}$, Sangeetha S, Earnest A, Bellamy R. The impact of malnutrition on survival and the CD4 count response in HIV-infected patients starting antiretroviral therapy. HIV Med. 2006;7(5):323-30.

8. Battistini Garcia SA, Guzman N. Acquired Immune Deficiency Syndrome CD4+ Count. In: StatPearls Publishing; 2021 Jan.

9. European AIDS Clinical Society. Last accessed date: 2021 April 26. Available from: https://www.eacsociety.org/files/guidelines-10.1_finaljan2021_1.pdf

10. Dieye TN, Vereecken C, Diallo AA, Ondoa P, Diaw PA, Camara M, et al. Absolute CD4 T-cell counting in resource-poor settings: direct volumetric measurements versus bead-based clinical flow cytometry instruments. J Acquir Immune Defic Syndr. 2005;39(1):32-7.

11. Faal M, Naidoo N, Glencross DK, Venter WD, Osih R. Providing immediate CD4 count results at HIV testing improves ART initiation. J Acquir Immune Defic Syndr. 2011;58(3):e54-9.

12. Eholié SP, Aoussi FE, Ouattara IS, Bissagnéné E, Anglaret X. HIV treatment and care in resourceconstrained environments: challenges for the next decade. J Int AIDS Soc. 2012;15(2):17334. 
13. The Joint United Nations Programme on HIV/AIDS. Last accessed date: 2021 April 26. Available from: https://www.unaids.org/en/resources/fact-sheet

14. Negedu-Momoh OR, Jegede FE, Yakubu A, Balogun O, Abdullahi M, Badru T, et al. Performance evaluation of BD FACSPresto ${ }^{\mathrm{TM}}$ point of care CD4 analyzer to enumerate CD4 counts for monitoring HIV infected individuals in Nigeria. PLoS One. 2017;12(5):e0178037.

15. Galiwango RM, Lubyayi L, Musoke R, Kalibbala S, Buwembo M, Kasule J, et al. Field evaluation of PIMA point-of-care CD4 testing in Rakai, Uganda. PLoS One. 2014;9(3):e88928.

16. Jani IV, Sitoe NE, Alfai ER, Chongo PL, Quevedo JI, Rocha BM, et al. Effect of point-of-care CD4 cell count tests on retention of patients and rates of antiretroviral therapy initiation in primary health clinics: an observational cohort study. Lancet. 2011;378(9802):1572-9.

17. Moran Z, Sacks JA, Frimpong FK, Frimpong AB, Ben Amor Y. Performance of the BD-FACS Presto for CD4 count and hemoglobin measurement in a district hospital and rural laboratory in Ghana. PLoS One. 2019;14(2):e0212684.

18. Denny T, Yogev R, Gelman R, Skuza C, Oleske J, Chadwick E, et al. Lymphocyte subsets in healthy children during the first 5 years of life. JAMA. 1992;267(11):1484- 8.

19. Gebremicael G, Belay Y, Girma F, Abreha Y, Gebreegziabxier A, Tesfaye S, et al. The performance of BD FACSPresto $^{\text {TM }}$ for CD4 T-cell count, CD4\% and hemoglobin concentration test in Ethiopia. PLoS One. 2017;12(4):e0176323.

\section{Figures}



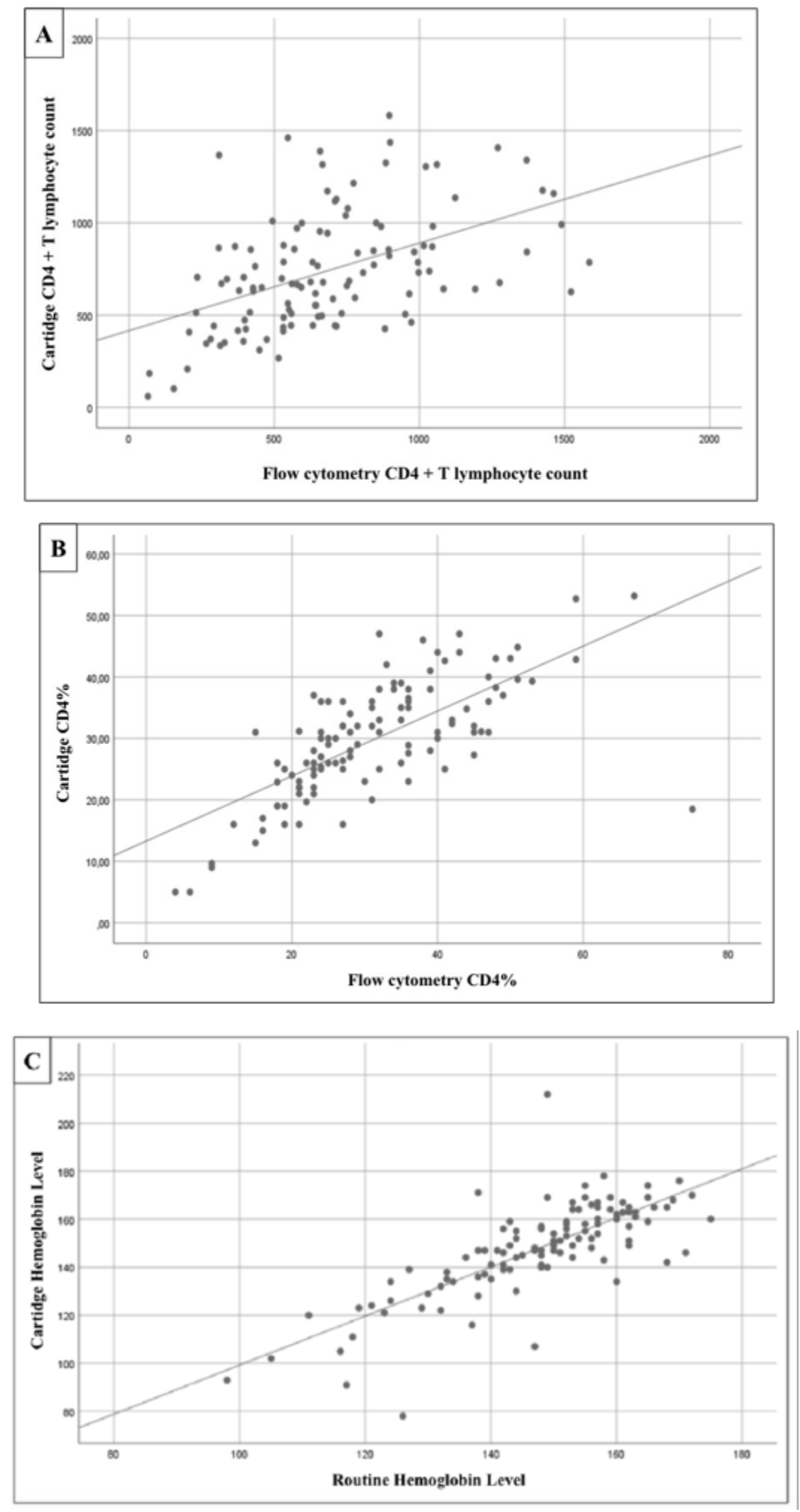

\section{Figure 1}

Spearman correlations graphics between two methods. CD4+ T lymphocyte count (A) , CD4+ T lymphocyte percentage (B), hemoglobin level (C) 

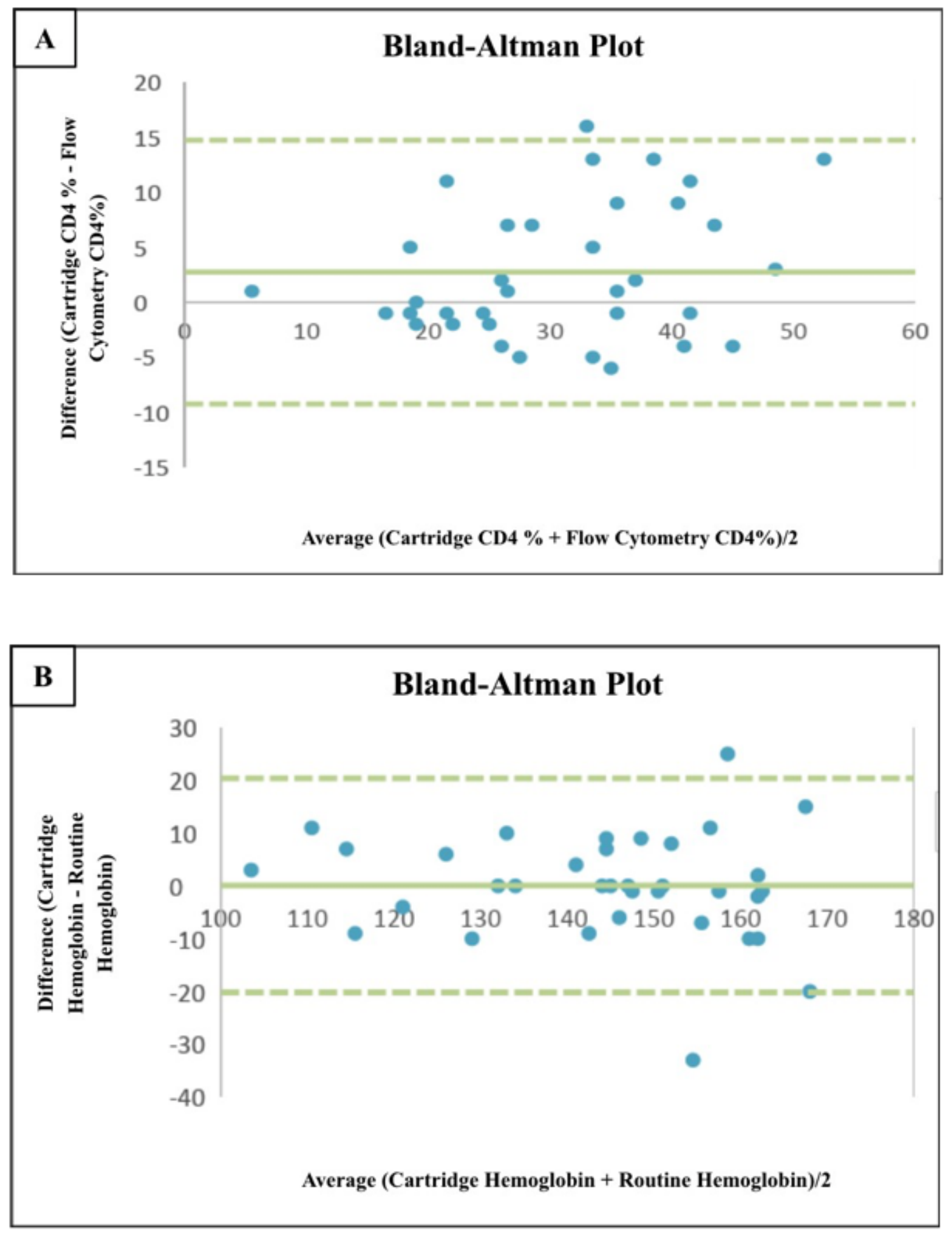

\section{Figure 2}

A: Bland-Altman plot comparing the flow cytometry and cartridge CD4 percentage measurements. B: Bland-Altman plot comparing the flow cytometry and cartridge hemoglobin measurements. The center line indicates the mean of differences and the upper and lower horizontal lines indicate the 1.96 times the standard deviations ( $95 \%$ of the data) 